\title{
Interferon $\beta$-1a prevented the development of clinically definite multiple sclerosis after a first demyelinating event
}

\author{
Jacobs LD, Beck RW, Simon JH, et al, and the CHAMPS Study Group. Intramuscular interferon beta-1a therapy initiated \\ during a first demyelinating event in multiple sclerosis. N Engl J Med 2000 Sep 28;343:898-904.
}

\section{QUESTION: In patients with a first confirmed demyelinating event, does interferon $\beta-1 \mathrm{a}$ reduce the incidence of clinically definite multiple sclerosis (MS)?}

\section{Design}

Randomised \{allocation concealed*\}†, blinded (patients, clinicians, and outcome assessors),* placebo controlled trial with 3 years of follow up (Controlled High Risk Subject Avonex Multiple Sclerosis Prevention Study [CHAMPS]). An interim analysis was planned.

\section{Setting}

50 clinical centres in North America.

\section{Patients}

383 patients (mean age 33 y, $75 \%$ women, $86 \%$ white) who had a first acute clinical demyelinating event confirmed by magnetic resonance imaging (MRI). Inclusion criteria were age 18-50 years; involvement of optic nerve, spinal cord, brain stem, or cerebellum; $\geqslant 2$ clinically silent brain lesions $\geqslant 3 \mathrm{~mm}$ in diameter; and symptom onset $<14$ days from corticosteroid treatment and $<27$ days from randomisation. Exclusion criterion was previous demyelinating event lasting $>48$ hours. Loss to follow up was $4 \%$, and $15 \%$ stopped early.

\section{Intervention}

All patients were given intravenous methylprednisolone, $1 \mathrm{~g} /$ day for 3 days, and then prednisone, $1 \mathrm{mg} / \mathrm{kg}$ of body weight per day orally for 11 days, followed up by tapering for 4 days. 193 patients were allocated to interferon $\beta-1 \mathrm{a}, 30 \mu \mathrm{g}$ /week by intramuscular injection, and 190 were allocated to placebo.

Main outcome measures

Development of clinically definite MS, changes in MRI findings, and adverse effects.

\section{Main results}

By 3 years, fewer patients in the interferon group than in the placebo group had developed clinically definite MS (adjusted $\mathrm{p}<0.001$ ) (table). Interferon group patients also had lower increases in lesion volume on MRI at 6 ,
Source of funding: Biogen.

For correspondence: Dr L D Jacobs,

Department of

Neurology, Buffalo

General Hospital, 100

NY 14203, USA. Fax

$+17168592430$
High Street, Buffalo,
12, and 18 months and fewer new or enlarging lesions measured with $\mathrm{T}_{2}$, weighted scans (mean $2.1 v 5.0$ lesions/patient at $18 \mathrm{mo}$ ) and gadolinium enhancing lesions at 6,12 , and 18 months (mean $0.4 v 1.4$ lesions/ patient at $18 \mathrm{mo}$ ) ( $\mathrm{p} \leqslant 0.03$ for all comparisons). Interferon group patients had a higher rate of the influenza-like syndrome during the first 6 months of treatment $(54 \% v 26 \%, \mathrm{p}<0.001)$ and a higher rate of depression $(20 \% v 13 \%, \mathrm{p}=0.05)$.
Interferon $\beta$-1 a v placebo to prevent multiple sclerosis (MS) after a first demyelinating event $\$$

\begin{tabular}{lllll} 
Outcome at 3 years & Interferon & Placebo & Adjusted RRR $(95 \% \mathrm{CI})^{5}$ & NNT (CI) \\
Definite MS & $35 \%$ & $50 \%$ & $51 \%(27$ to 67$)$ & $4(2$ to 8$)$ \\
\hline
\end{tabular}

¥Abbreviations defined in glossary; NNT and its $\mathrm{Cl}$ calculated from data in article.

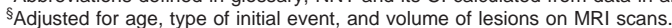

\section{Conclusion}

Patients with a first demyelinating event and lesions on magnetic resonance imaging who received interferon $\beta$-la had a lower incidence of clinically definite multiple sclerosis by 3 years.

*See glossary.

$\dagger$ Information provided by author.

\section{COMMENTARY}

Jacobs $e t$ al have published an important paper. They show that interferon $\beta$-la treatment of patients with a single symptom suggestive of MS and $\geqslant 2$ lesions on MRI that are strongly suggestive of MS delays the appearance of the second symptom, thus delaying the diagnosis of MS (ie, to satisfy the criterion for dissemination of white matter lesions in time and space).

Previous studies with interferons and glatiramer acetate have shown that in relapsing MS the time to next attack was prolonged by treatment. ${ }^{1-3}$ The results of this study were expected therefore to be in favour of interferon treatment. Serious side effects of this treatment are flu-like symptoms, liver function test abnormalities, and leukopenia. Liver necrosis occurs rarely in these patients during treatment.

If accepted as an indication for the earliest possible treatment for MS, this study could result in a more effective overall use of disease modifying drugs in MS. As the authors state in their discussion, other studies have shown that frequent relapses and the number and extent of lesions on MRI have an influence on the long term outcome of the disease. Therefore, significantly and persistently reducing the relapse rate, prolonging the interval between relapses, and reducing the number of new lesions on MRI could have a major effect on the clinical outcome of the disease. However, as the authors state, such a conclusion needs to be supported by long term studies.

\section{Donald Paty, MD University of British Columbia Vancouver, British Columbia, Canada}

1 Johnson KP, Brooks BR, Cohen JA, et al. Copolymer 1 reduces relapse rate and improves disability in relapsingremitting multiple sclerosis: results of a phase III multicenter, double-blind, placebo-controlled trial. The copolymer 1 multiple sclerosis study group. Neurology 1995;45:1268-76.

2 Interferon beta-1a in the treatment of multiple sclerosis: final outcome of the randomized controlled trial. The IFNB multiple sclerosis study group and the University of British Columbia MS/MRI analysis group. Neurology 1995;45:127785.

3 Randomised double-blind placebo-controlled study of interferon $\beta$-1a in relapsing/remitting multiple sclerosis. Lancet 1998;352:1498-504. 